Historia y comunicación social

ISSN: $1137-0734$

http://dx.doi.org/10.5209/hics.66674

\title{
Movimiento obreroy sindicatos. Un análisis desde el periodismo religioso en el tardofranquismo
}

\author{
Jesús Sánchez-Camacho; Ninfa Watt²; José David Urchaga-Litago ${ }^{3}$
}

Recibido el: 30 de enero de 2020 / Aceptado: 22 de enero de 2021

Resumen. En febrero de 1971, se publica la Ley Sindical 2/1971, una disposición que solo contiene novedades de carácter administrativo, sin establecer la libertad de asociación y participación ciudadana. En los últimos años del franquismo habían surgido colectivos que defendían los derechos de los trabajadores a través de huelgas y manifestaciones. La Doctrina Social de la Iglesia también defendió sus derechos y algunos sectores cristianos participaron en las revueltas. El periodismo religioso de aquel momento tuvo presente este tema en su agenda. Así lo hizo Vida Nueva, uno de los semanarios de carácter social y religioso más reconocidos en la prensa católica. En esta investigación se analiza el movimiento obrero, los derechos sindicales y su impacto en la sociedad e Iglesia española a través de los editoriales de la revista Vida Nueva entre 1968 y 1975. Las conclusiones del trabajo indican las propuestas de la revista orientadas hacia la defensa del mundo obrero, la promoción de la libertad, la autonomía y la representatividad de los sindicatos.

Palabras clave: movimiento obrero; sindicatos; tardofranquismo; periodismo religioso; línea editorial.

\section{[en] Workers' movement and trade unions. An Analysis from the Religious press in Late Francoism}

Abstract. In February 1971, the Trade Union Law 2/1971 was enacted. It was a disposition that only contained administrative innovations, without establishing freedom of association and citizen participation. In the last years of Franco's regime, some collectives had emerged to defend workers' rights through strikes and demonstrations. The Social Doctrine of the Church also defended their rights, and some Christian sectors participated in the revolts. Religious journalism at that time had this issue on its agenda. So did Vida Nueva, one of the most prominent social and religious weekly magazines in the Catholic press. This research analyses the workers' movement, trade union rights, and their impact on Spanish society and the Church. It has been studied in the editorials of Vida Nueva from 1968 to 1975 . The conclusions of the study reveal the proposals of the magazine aimed at the defence of the working class, the promotion of freedom, the autonomy, and the representativeness of trade unions.

Keywords: workers movement; trade unions; late Francoism; religious journalism; editorial line.

Sumario: 1. Introducción. 2. Metodología. 3. Análisis cuantitativo. 4. Análisis cualitativo. 4.1 Movimiento obrero. 4.2 Sindicatos. 5. Conclusiones. 6. Bibliografía.

Cómo citar: Sánchez-Camacho, J.; Watt, N.; Urchaga-Litago, J. D. (2020) Movimiento obrero y sindicatos. Un análisis desde el periodismo religioso en el tardofranquismo, Historia y comunicación social 26(1), 225-236.

\section{Introducción}

En España durante el tardofranquismo, la publicación de Ley Sindical 2/1971 supuso la introducción de algunas novedades de naturaleza administrativa. Sin embargo, no estableció la libertad de asociación y participación ciudadana, defendida por colectivos que se manifestaban a favor de los derechos del trabajador. Previamente, la Ley de 1938 había establecido el Sindicato Vertical, que sería la única organización sindical existente en España durante la dictadura de Francisco Franco.

Universidad Pontificia Comillas

E-mail: jscamacho@comillas.edu

ORCID: https://orcid.org/0000-0002-9087-6959

2 Universidad Internacional de La Rioja

E-mail: ninfa.watt@unir.net

ORCID: https://orcid.org/0000-0003-1699-2318

3 Universidad Pontificia de Salamanca

E-mail: jdurchagali@upsa.es

ORCID: https://orcid.org/0000-0001-6624-070X

Hist. comun. soc. 26(1) 2021: 225-236 
Mientras que la Doctrina Social de la Iglesia promovió los derechos de la clase trabajadora (Van Gestel, 1962), algunos grupos de la comunidad católica participaron en revueltas (Montero, 2009: 58). La problemática no fue ajena a la prensa católica, que abordó las propuestas del Concilio Vaticano II y los documentos oficiales de los papas al hilo de los acontecimientos sociales. Ese fue el caso de uno de los semanarios católicos más relevantes en aquella época: Vida Nueva, un semanario de información general y religiosa, que realiza específicamente un tratamiento de la información de la Iglesia católica por medio de distintos géneros periodísticos como la noticia, la crónica, el reportaje, la entrevista, el editorial y la opinión (Martínez Hernando, 1973, 7-8). En los años del posconcilio, a través de su director José Luis Martín Descalzo y un equipo de redacción compuesto por periodistas como Bernardino M. Hernando, Joaquín Luis Ortega y Antonio Pelayo, intentarán fomentar la renovación de la Iglesia en España a la luz de los documentos del Concilio Vaticano II (Editorial, $\mathrm{n}^{\circ}$ 655, 07-12-1968: 5).

El objetivo de este trabajo es examinar el tratamiento del movimiento obrero, los derechos sindicales y su impacto en la sociedad e Iglesia española, a través de la línea editorial de la revista Vida Nueva. El periodo de estudio se encuadra entre el 2 de noviembre de 1968 (número 650) y el 3 de enero de 1976 (número 1011). Las fuentes primarias de la investigación son los editoriales de la revista, ya que este es el género periodístico que se ocupa de valorar hechos, antecedentes, opiniones, juicios, propuestas y predicciones de futuro del hecho noticioso (Santamaría, 1990: 56).

Las siguientes preguntas específicas de investigación han impulsado la reflexión inicial del análisis, cuyas respuestas estarán presentes en las conclusiones del trabajo: ¿cómo fue el tratamiento periodístico de Vida Nueva en sus editoriales al referirse al movimiento obrero y los sindicatos?; ¿qué propuestas hizo?; ¿cómo evaluó la Ley Sindical 2/1971 de 17 de febrero?; ¿cómo valoró el pronunciamiento de la Iglesia sobre el proyecto de Ley?; ¿cuál es el enfoque de los presbíteros, religiosos y laicos implicados en el mundo del trabajo?

Hay que remontarse al Sexenio Democrático (1868-1874) para establecer en España el nacimiento del movimiento obrero. Concretamente, el acontecimiento que marca su inicio es la celebración del Congreso Obrero de Barcelona de 1870, donde se funda la Federación Regional Española de la Primera Internacional (Rodríguez Labandeira, 1999: 218-229). Casi veinte años más tarde emerge la organización sindical española socialista, fundada en 1888 bajo la denominación de la Unión General de Trabajadores (Castillo, 2008: 90-97); y la anarcosindicalista, llamada Confederación Nacional del Trabajo, fundada en 1910 (Peirats Valls, 1991: 1316). Igualmente, el espíritu del movimiento obrero está presente en la Segunda República (Núñez de Arenas y Tuñón de Lara, 1970: 243-254).

Tras la Guerra Civil (1936-1939), cuando el Régimen de Francisco Franco Bahamonde concentra todo el poder en su persona (Tusell, 1989: 32), la Ley del 9 de marzo de 1938 regula los derechos y deberes de los trabajadores y codifica los sindicatos verticales (Decreto 779/1967, 21 abril, 1967). De hecho, uno de los tres sólidos pilares en el que se funda el Régimen de Franco es precisamente en la FET y de las JONS (Falange Española Tradicionalista y de las Juntas de Ofensiva Nacional Sindicalista). Las otras dos columnas son el Ejército y la Iglesia Católica española (Tusell, 1990: 569-570), institución que inicialmente apoya al Régimen de Franco desde la sublevación militar de julio de 1936 (Casanova Ruiz, 2005). A pesar de las limitaciones al asociacionismo, en el tardofranquismo surge Comisiones Obreras, que tiene su germen en colectivos contrarios al Régimen. Estos grupos participan en buena medida en las protestas de los conflictos laborales, como en la huelga minera de Asturias en 1962, en el Partido Comunista de España y en movimientos cristianos obreros como la Juventud Obrera Cristiana y la Hermandad Obrera de Acción Católica (Montero, 2009: 67-98).

En los últimos años del franquismo, la conflictividad laboral supone un desafío para la estabilidad e imagen del Régimen. Hacía más de un siglo que las manifestaciones del movimiento obrero habían irrumpido con fuerza en el resto del continente europeo. Particularmente, en España, las reivindicaciones y movilizaciones sociales se registran por primera vez en la década de los 50 (Ortega, 1979: 675) y están especialmente presentes en la década de los 60 y en la primera mitad de los 70, en las que incluso participan presbíteros y diferentes grupos cristianos (Tusell, 1984: 216).

En efecto, la comunidad católica no vive al margen de los profundos cambios de la primera mitad del siglo XX. La renovación teológica se desarrolla paralelamente a la experiencia de los sacerdotes obreros (Laboa, 2002: 321-322) y la jerarquía eclesial muestra mayor interés por el mundo del trabajo. De hecho, ya a finales del siglo XIX, teniendo como horizonte las consecuencias sociales de la industrialización, se publica la Carta Encíclica Rerum novarum, que respalda el derecho a formar asociaciones de obreros (León XIII, 1891). Años más tarde, se publica la Carta Encíclica Il fermo proposito, que supone un avance considerable para el asociacionismo religioso estableciendo las bases de la Acción Católica (Pío X, 1905). Será solo el inicio de la divulgación de una serie de documentos preocupados por la cuestión social ${ }^{4}$. Aunque los orígenes de la defensa

Desde la publicación de la Carta Encíclica Rerum Novarum, la Doctrina Social de la Iglesia ha articulado una prolífica reflexión sobre la situación de los obreros (León XIII, 1891). En esa línea continuaron documentos como la Carta Encíclica Quadragesimo Anno, sobre la restauración del orden social (Pío XI, 1931); la Carta Encíclica Mater et Magistra, sobre el desarrollo de la cuestión social a la luz de la doctrina cristiana (Juan XXIII, 1961); la Constitución Pastoral Gaudium et Spes (Concilio Vaticano II, GS 75) que, entre otras cosas, aboga por la colaboración de todos los ciudadanos en la vida pública; y la Carta Encíclica Populorum Progressio, sobre la necesidad de promover el desarrollo de los pueblos (Pablo VI, 1967: 27-28, 70). En relación con los sindicatos, la Carta Encíclica Quadragesimo Anno (Pío XI, 1931: 35, 92-93), la Carta Encíclica Mater 
católica del sindicalismo en España se remonten a finales del siglo XIX (Cuenca Toribio, 2001), y comienza a emerger un catolicismo social tras la publicación de la encíclica Rerum Novarum, es en el tardofranquismo cuando la jerarquía católica en España empieza a publicar documentos sobre el derecho sindical (Monereo Pérez, 2010). Estos documentos tendrán una significativa repercusión entre sectores de presbíteros, religiosos y laicos católicos, que apoyan a las organizaciones sindicales y toman una actitud crítica hacia el Régimen 5 .

En concreto, a mediados del siglo XX se inician las primeras manifestaciones en el sector obrero, en las que los militantes cristianos españoles también participan en las reivindicaciones (Ortega, 1979: 675). Entre 1946 y 1947, se originan los Movimientos Especializados de la Acción Católica, como la Hermandad Obrera de Acción Católica o la Juventud Obrera Cristiana, que demandan la defensa de los derechos de los trabajadores y se movilizan participando en protestas (Montero, 2009: 58-74, 89). Al comienzo de la década de los setenta, la tensión social crece. Se avivan las huelgas en la industria del carbón y en el sector de la construcción, y aumentan las protestas en las calles protagonizadas especialmente por obreros, universitarios, religiosos y sacerdotes (Tusell, 1989: 199-202).

La Iglesia católica en España es cada vez más plural. Si anteriormente la representación jerárquica de la Iglesia había estado presente en los actos públicos organizados por el Régimen, a partir de finales de los años sesenta se observa un progresivo distanciamiento entre ambas instituciones (Castillo Esparcia; y Castillero Ostio, 2019: 75). Sin embargo, en respuesta a los movimientos eclesiales que reivindican mayor justicia, un sector del catolicismo se muestra reticente a estas reivindicaciones y equipara el pensamiento de este tipo de organizaciones católicas con la ideología marxista (Montero, 2009: 91-98). Incluso, grupos concretos como Fuerza Nueva, la FET o los Guerrilleros de Cristo Rey revelan dicha discrepancia con ataques verbales y violencia física (Payne, 1987: 586).

En ese contexto, se publica la Ley Sindical 2/1971 que, pese a incluir novedades de carácter administrativo, seguirá concediendo la misma vigencia a los Sindicatos Verticales, sin establecer la libertad de asociación y participación ciudadana (Ley Sindical 2/1971 de 17 de febrero, 1971). Posteriormente, aumenta la represión policial en manifestaciones provenientes del sector obrero y universitario. Y, como réplica a las protestas callejeras, grupos de extrema derecha intensifican su acción violenta, atentando contra librerías y locales considerados de tendencias izquierdistas (Payne, 1987: 606). Luis Carrero Blanco, nombrado presidente del Gobierno en junio de 1973, desempeña su mandato con fidelidad a los principios del Movimiento. Tras su asesinato, pasa a sucederle Carlos Arias Navarro, que inició su mandato pronunciando un discurso en el que se vislumbraba un programa reformista que no tuvo aplicación real (Tusell, 1990: 767).

Pese a las esperanzas despertadas en el sector aperturista por el nuevo presidente, promesas como la reforma en el campo sindical quedan sin cumplirse (Orella Martínez, 2009: 847-848). Se aprueba el Estatuto Jurídico del Derecho de Asociación Política, que sigue limitando la libertad de las asociaciones debido a la exigencia de la autorización y el control organizativo del Régimen (Decreto ley 7/1974 de 21 de diciembre, 1974).

En este contexto, Vida Nueva, intenta impulsar en España la renovación promovida por el Concilio Vaticano II. A pesar de ser una publicación independiente, algunos sectores católicos la observan como un órgano oficioso de la Conferencia Episcopal Española (Editorial, $n^{\circ}$ 1000, 11/18-10-1975: 4-9), debido a su afinidad con los obispos reformistas que ocupaban puestos relevantes en el tercer trienio de dicha institución ${ }^{6}$. Pero el semanario no solo cubre y editorializa sobre la información religiosa. A la luz de la doctrina social de la Iglesia, la revista desempeña un papel crítico en la sociedad. Sin embargo, Martín Descalzo llega a reconocer que, debido a la represión de la dictadura, se ve obligado a "practicar el arte de decir medias verdades o de rebozar las verdades enteras con abundante ración de vaselina" (Editorial, $\mathrm{n}^{\circ}$ 1011, 03-01-1976: 5) .

et Magistra (Juan XXIII, 1961: 48, 100, 102) y la Carta Encíclica Populorum Progressio (Pablo VI, 1967: 39) valoran positivamente la existencia de las asociaciones sindicales para la defensa del obrero. Asimismo, la Constitución Pastoral Gaudium et Spes, reconoce el derecho de los obreros a fundar asociaciones que representen al trabajador (Concilio Vaticano II, GS 68).

En el tardofranquismo, los obispos se muestran especialmente sensibles con la pobreza y el mundo obrero, de manera que comienzan a publicar documentos de carácter social. El primer documento significativo del episcopado español se publica el 29 de junio de 1966. Con La Iglesia y el orden temporal a la luz del Concilio, los obispos desean perfeccionar la situación social en España (Ortega, 1979: 690). Un año más tarde, la Conferencia Episcopal anuncia una reforma de los estatutos de la Acción Católica lanzando la Actualización del apostolado seglar en España (Martín de Santa Olalla y Serrano Oceja, 2016: 36-38). Después, a través de los Principios cristianos relativos al sindicalismo (Conferencia Episcopal Española, 1968), los obispos estudian la representatividad sindical; y con las Normas provisionales para los sacerdotes en el trabajo (1968), el episcopado autoriza el envío de presbíteros al mundo del trabajo para evangelizar a la clase obrera (Martín de Santa Olalla y Serrano Oceja, 2016: 39-43). La Nota sobre la Ley Sindical, texto acordado en la XI Asamblea Plenaria de la Conferencia Episcopal Española, reconoce la urgente necesidad de una nueva ley sindical que satisfaga las aspiraciones del mundo del trabajo (Conferencia Episcopal Española, 1969). El 11 de julio de 1970 se publica La Iglesia y los pobres, un documento que adquiere una importancia especial al orientar la misión de la Iglesia preferentemente hacia los excluidos. El texto alude al "derecho que todo hombre tiene a asociarse y reunirse libremente para fines lícitos, como es la promoción de sus intereses profesionales dentro de auténticos sindicatos representativos, y a la intervención en la cosa pública a través de cauces eficaces de participación política" (Conferencia Episcopal Española, 1970).

E1 7 de marzo de 1972, el cardenal Vicente Enrique y Tarancón, arzobispo de Madrid-Alcalá, comienza su periodo de presidencia de la Conferencia Episcopal Española (Cárcel Ortí, 1997: 429-439, 452-459). Para Vida Nueva, la Iglesia española da pasos fundamentales en ese tercer trienio, valorando el esfuerzo de la jerarquía por implicarse en la realidad social del país (Editorial, $n^{\circ}$ 971, 01-03-1975: 5-7).

Aunque la Ley de Prensa e Imprenta de 1966 pone fin a la censura previa de la Ley de Prensa de 1938, mantiene secuestros administrativos y sanciones tanto para las empresas informativas como para los periodistas (Ley 14/1966, de 18 de marzo). De las tres sanciones y dos secuestros recibidos en la redacción de la revista (Vida Nueva, $\mathrm{n}^{\circ} 736,27-06-1970$ ), el dato que cobra mayor interés para este estudio es la sanción impuesta por 


\section{Metodología}

En esta investigación se ha utilizado la técnica del análisis de contenido (García Galera y Berganza Conde, 2005: 37-38, 52). Entre los distintos caminos metodológicos del campo de la Comunicación Mediática se ha optado por una metodología mixta (Hernández-Sampieri y Mendoza Torrres, 2018): a través del método cuantitativo se han recopilado y medido los editoriales; a través cualitativo se han interpretado (García Galera y Berganza Conde, 2005: 27-31; Sánchez Aranda, 2005: 207-228; Urchaga, 2009; Wimmer y Dominick, 1996: $49,51,146)$.

Las categorías de estudio se extraen del trabajo de Watt, Rey, y Urchaga (2010) y de Sánchez-Camacho (2018), que realizan análisis de contenido del semanario Vida Nueva. Las categorías principales han sido Movimiento obrero y Sindicatos. Mientras que la primera incluye los editoriales que aluden a las protestas de asalariados para defender sus derechos como trabajadores, la segunda se refiere al debate relacionado con la asociación de trabajadores para la defensa y promoción de sus intereses laborales.

Además de estas categorías, se han seleccionado otras como Libertad, Justicia social, Participación: política, Participación: ciudadana, Participación: eclesial, Derechos humanos, Diálogo, Reflexión, Espíritu evangélico, Reconciliación, Cambio, No a la solución militar/fuerza represiva, No a la violencia No a la confrontación, No a la revolución/subversión. Estas últimas categorías se incluyen para estudiar en qué manera co-ocurren con Movimiento obrero y Sindicatos, con el objeto de establecer relaciones entre las variables de estudio.

Los resultados de la investigación se exponen en los siguientes apartados. Primeramente, a través de la exposición del análisis cuantitativo, donde se cuantifica la presencia de los temas. Después, se introduce el análisis cualitativo, en el que se presenta y analiza los mensajes de los editoriales.

\section{Análisis cuantitativo}

En los editoriales de Vida Nueva no solo está presente la temática religiosa, sino también la social, política, económica y cultural de la España tardofranquista. Al abordar la cuestión social, la revista pone de relieve el impacto del movimiento obrero y aporta propuestas relativas a los problemas laborales del país. De los 360 editoriales analizados del 2 de noviembre de 1968 (número 650) al 3 de enero de 1976 (número 1011), el Movimiento obrero es una categoría presente 16 veces $(4,4 \%)$ en los editoriales del semanario. Los Sindicatos aparecen en 14 textos (3,9\%). En este apartado de la investigación, mostramos los datos estadísticos relacionados con estas dos categorías. La Tabla 1 expone los datos de frecuencias de las categorías analizadas y sus porcentajes globales de los editoriales de Vida Nueva sobre el Movimiento obrero y los Sindicatos:

Tabla 1. Datos de frecuencias de las categorías

\begin{tabular}{|c|c|c|c|c|c|c|c|c|c|c|c|}
\hline & & $1968^{1}$ & 1969 & 1970 & 1971 & 1972 & 1973 & 1974 & 1975 & $1976^{2}$ & Total \\
\hline Movimiento obrero & $\mathrm{N}^{\mathrm{o}}$ & 0 & 0 & 3 & 3 & 1 & 1 & 4 & 4 & 0 & 16 \\
\hline Sindicatos & $\mathrm{N}^{\mathrm{o}}$ & 0 & 5 & 4 & 1 & 1 & 0 & 1 & 2 & 0 & 14 \\
\hline
\end{tabular}

En la Tabla 1 se observa que ambas categorías no son tratadas de la misma forma por la revista a lo largo de los años: si la frecuencia de los Sindicatos es mayor en 1969 y 1970; en torno a 1974 y 1975, el Movimiento obrero es un tema más frecuente. Hay que subrayar las ausencias de estas categorías. Solo en 1969, la revista no aborda la temática del Movimiento obrero. Por su parte, los Sindicatos no aparecen en ningún editorial de 1973. Estas insignificantes ausencias temáticas, indican que, a lo largo de los años del tardofranquismo, Vida Nueva no se olvida de las dos categorías estudiadas. Igualmente, hay que destacar que 1969 y 1970 son los años donde están más presentes los Sindicatos. El semanario le da una mayor importancia a esta categoría debido a que eran momentos previos a la publicación de la Ley Sindical 2/1971. Por su parte, los años más representativos para la categoría Movimiento obrero son 1974 y 1975, fechas marcadas por el Decreto ley 7/1974 y el final de la dictadura. El Gráfico 1 muestra los porcentajes por años del tratamiento del Movimiento obrero y los Sindicatos en los editoriales del semanario: 


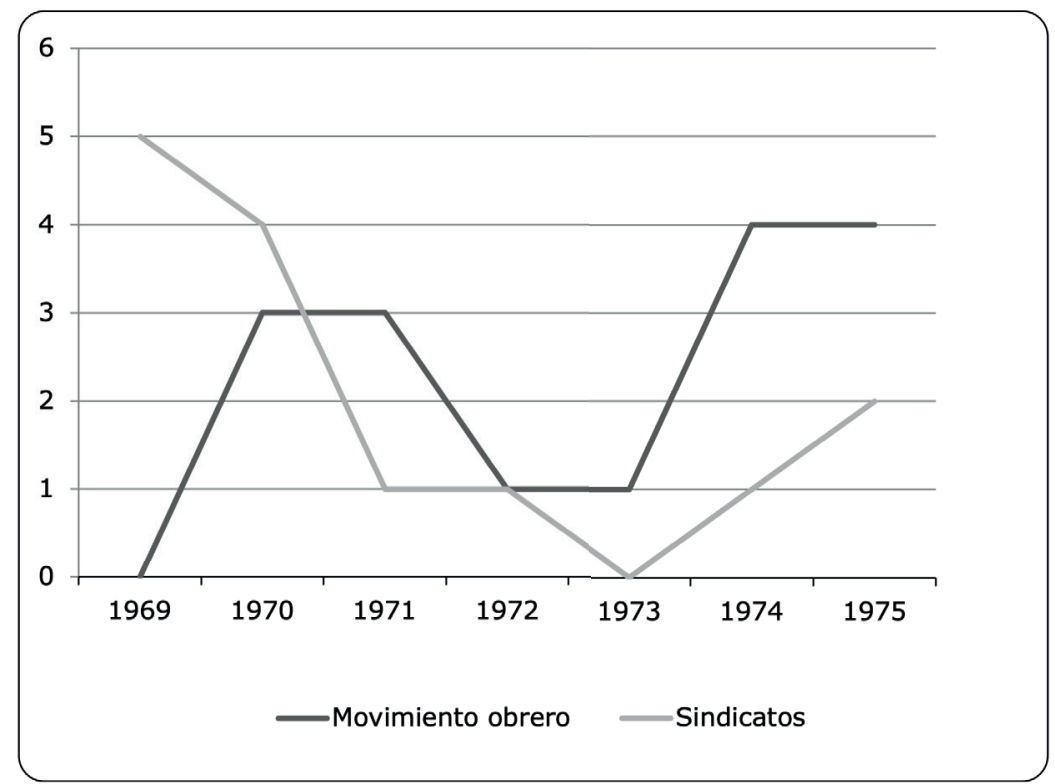

Figura 1. Gráfico de frecuencias por años

La Tabla 2 revela los porcentajes co-ocurrentes con otras categorías halladas en los mismos editoriales en los que aparecen el Movimiento obrero y los Sindicatos. De estos resultados se infiere que el Movimiento obrero aparece principalmente en editoriales cuyos textos reclaman un 60\% Justicia social y Espíritu evangélico; un $47 \%$, Libertad; un $40 \%$, No a la solución militar/fuerza represiva y No a la violencia; un $33 \%$, Participación: política, No a la confrontación y No a la revolución/subversión; y un 27 \%, Diálogo.

La categoría Sindicatos co-ocurre con editoriales que en un 64\% llama a la Justicia social; un 50\%, a la Participación: eclesial, Espíritu evangélico y Cambio; un 36\%, a la Participación: política, Participación: ciudadana, Derechos humanos, No: solución militar/fuerza represiva y No a la violencia; y un $29 \%$, a la Reflexión, Reconciliación y No a la confrontación.

Tabla 2. Porcentajes co-ocurrentes de las categorías con propuestas y juicios de valor

\begin{tabular}{lcc}
\hline & Movimiento obrero \% & Sindicatos \% \\
\hline Libertad & 47 & 21 \\
Justicia social & 60 & 64 \\
Participación: política & 33 & 36 \\
Participación: ciudadana & 20 & 36 \\
Participación: eclesial & 13 & 50 \\
Derechos humanos & 20 & 36 \\
Diálogo & 27 & 0 \\
Reflexión & 13 & 29 \\
Espíritu Evangélico & 60 & 50 \\
Reconciliación & 20 & 29 \\
Cambio & 20 & 50 \\
No: sol. militar/f. represiva & 40 & 36 \\
No a la violencia & 40 & 36 \\
No a la confrontación & 33 & 29 \\
No revolución/subversión & 33 & 14 \\
\hline
\end{tabular}

En consecuencia, la revista social y religiosa Vida Nueva afronta la temática del movimiento obrero y los sindicatos en su línea editorial, promoviendo la participación ciudadana, apostando por las asociaciones sindicales, y fomentando valores como la justicia social, libertad, autonomía, diálogo y paz. La inferencia de estos resultados en el análisis cualitativo conducirán a unas conclusiones más específicas. 


\section{Análisis cualitativo}

A continuación, se muestra el estudio cualitativo de las categorías. El objeto de este análisis es ir más allá de los resultados estadísticos, aportando un componente interpretativo de los editoriales a través de inferencias que conducirán a las conclusiones del trabajo.

\subsection{Movimiento obrero}

Los editoriales de la revista citan al Movimiento obrero, sobre todo en 1974 y 1975, años donde se publica el Decreto ley 7/1974 y finaliza el periodo franquista. Además de confirmar en el análisis cuantitativo que esta categoría no está significativamente presente en los editoriales de Vida Nueva, hay que constatar que son solamente 3 los textos que abordan de manera más amplia el tema. Los 13 editoriales restantes se limitan a mencionar al Movimiento obrero al tratar otra temática colateral. Sin embargo, la revista defiende los derechos de los trabajadores, proponiendo mayor Justicia social, Espíritu evangélico, Libertad, No a la solución militar/fuerza represiva, No a la violencia, Participación: política, No a la confrontación, No a la revolución/ subversión y Diálogo.

El editorial del número 719, titulado "El coraje de seguir", es uno de los tres textos que dedica más líneas al Movimiento obrero. Representa un reconocimiento a los presbíteros que, vinculados al mundo del trabajador, vieron suprimida su experiencia pastoral ${ }^{8}$ : "Ese rostro que veis ahí —curtido y sonriente, duro y pacífico a la vez- es el del Padre Low". El editorialista se hace eco del llamado Padre Jacques Loew, pionero de los sacerdotes en la defensa de los obreros, y cargador en el puerto de Marsella durante catorce años. Este presbítero, vinculando la evangelización con la justicia social, quiso reconciliar el llamado mundo temporal con el espíritu y misión evangélica de la Iglesia. No obstante, como apunta el editorial, fue "ferozmente golpeado por la decisión que suprimía a los curas obreros en 1954". Sin embargo, en 1970, Pablo VI nombró a Jacques Loew como director de sus ejercicios espirituales. El semanario cree que, si el presbítero no ha cambiado de estilo, "en la Capilla Matilde se habrán oído cosas como estas" relacionadas con el mundo del trabajo y la misión de la Iglesia:

'El trabajo manual marca el paso de un evangelio predicado a un evangelio vivido'.

'Ni la lectura del Capital ni la del Catecismo del Concilio de Trento han sido capaces de convertir a nadie, ni al marxismo ni al comunismo'.

'Si estamos ante un estado de misión, los métodos tradicionales no serán suficientes para que entren los peces en la red del pescador'.

'Se suprime a los curas obreros por algunos errores cometidos. Durante años, nosotros hemos visto que los curas han cometido disparates comprometiéndose en favor de los ricos y los capitalistas. ¿Es que se les ha suprimido por eso?'.

'La visión de los obreros que se quedan como ovejas sin pastor me oprime. ¿Dónde encontrarán a Cristo, pobre y amigo, de los humildes, estos españoles, estos italianos, estos armenios, que no sienten hacia el sacerdote y hacia la Iglesia más que desprecio?'

'La batalla de Dios se libra hoy en el mundo de lo temporal, alrededor de la cuestión de salarios, de sindicalismo, de tráfico comercial, de organización administrativa, de urbanismo'.

'Una Acción Católica limitada a lo espiritual, a lo sobrenatural, no pisa terreno firme. Nosotros vivimos en lo temporal, en lo material; el olvidarlo hace el juego al materialismo' (Editorial, $\mathrm{n}^{\circ} 719,28-02-1970: 5$ ).

La revista considera que se ha hecho justicia con el clérigo obrero, ya que con dicho gesto el Pontífice marca el camino eclesial: "Una vez más, Pablo VI ha querido elegir, para la revisión anual de su vida y la de sus más próximos colaboradores, no a los hombres aquietadores, sino a hombres inquietos e inquietadores" (Editorial, $\mathrm{n}^{\mathrm{o}}$ 719, 28-02-1970: 5). De este modo, el semanario saca a la luz implícitamente la vinculación existente entre la evangelización y la justicia social ${ }^{9}$.

El editorial del número 727, titulado "Las cuatro caras de una fecha", es el más controvertido de todos los publicados por el semanario en relación con el mundo laboral, ya que tuvo como consecuencia la primera

En 1954, el Santo Oficio prohibe la experiencia de los sacerdotes obreros: "La Santa Sede estima que para evangelizar los ambientes obreros no es indispensable mandar sacerdotes como obreros a los medios de trabajo, y que no es posible sacrificar la concepción tradicional del sacedorcio a este objetivo" (Hernández Díaz, 2015: 469). La polémica en torno al asunto se acentúa en diversos ámbitos eclesiales. Por ejemplo, en el campo de la teología, se retiró la licencia a algunos profesores que promovían la compatibilidad de la evangelización y la defensa de la justicia social a través del trabajo de los sacerdotes en contextos obreros (Laboa, 2002: 321-322).

Este fue un asunto bastante incomprendido en algunos sectores del catolicismo español, que limitaba el campo de acción de la Iglesia al orden religioso, acusando a la institución eclesial de inmiscuirse en asuntos públicos. Sin embargo, el tema estuvo especialmente presente en el Concilio Vaticano II, sin considerar la fe y los llamados asuntos temporales como dos realidades contrapuestas, sino complementarias (Concilio Vaticano II, Gaudium et spes, 36, 38, 41, 43, 76; Apostolicam actuositatem, 4-7). 
sanción de la revista tras la publicación de la Ley de Prensa e Imprenta (Ley 14/1966, de 18 de marzo $)^{10}$. La revista, haciendo referencia a "las dos Españas" se pregunta si todos los ciudadanos celebrarán "el mismo 1 de mayo" o si cada uno conmemorará un "1 de mayo particular y... discordante del de nuestro vecino". El semanario profundiza sobre el Día Internacional de los Trabajadores en España y, en algunos casos, haciendo uso de un lenguaje irónico, considera cuatro formas de vivir dicho acontecimiento:

Está, en primer lugar, el '1 de mayo de la excursión y la tortilla de patatas'. Esta acaparará, si no nos equivocamos, la mayor proporción de españoles. Abogados, ingenieros, metalúrgicos y oficinistas, tomarán su autobús o su seiscientos, su Simca 1.000 o trenecillo y se irán al campo a gozar de ese domingo fuera de serie que les cae en medio de la semana. Vivirán ese gozo de no trabajar en la Fiesta del Trabajo y se bañarán en playas o lagos o gozarán del primer sol del verano anticipado. Ninguno de ellos pensará en las luchas del ayer o en las batallas del mañana; ni la justicia ni la distribución de la renta nacional enturbiarán su gozo. Las alegres canciones del transistor serán su único himno y si, equivocadamente, al buscar Karina o Julio Iglesias, 'sale' un sermón o discurso, girarán la aguja de su radio para que nadie, hablando del trabajo, turbe la paz de su descanso (Editorial, $\mathrm{n}^{\mathrm{o}}$ 727, 27-04-1970: 5).

Tras esta caricatura del español que convierte en ocio el Día Internacional de los Trabajadores, la revista se centra en la Demostración sindical, celebrada anualmente en el Estadio Santiago Bernabéu, en el que se organizaba un espectáculo donde se realizaban ejercicios gimnásticos y folclóricos:

Estará en segundo lugar 'el 1 de mayo del Bernabéu'. Allí unos miles de productores mostrarán una bella exhibición de su fuerza o sus danzas ante otros miles de espectadores y algunos miles más de televidentes. Todo será triunfal y alegre, solo rostros felices mostrarán la pantalla. El eco de esos cien conflictos laborales que actualmente existen en nuestro país no enturbiará la fiesta. La jornada conmemorativa del trabajo será allí bien distante de las que cuenta la historia en tiempos de lucha y manifestaciones callejeras. No habrá gritos ni disparos. Nadie recordará allí que -como escribía hace días España Económica- 'la participación de los trabajadores en la renta nacional es, entre nosotros, una de las más bajas de Europa y que los empresarios no cederán hasta que no se encuentren obligados a ello' (Editorial, nº 727, 27-04-1970: 5).

Por otro lado, el semanario alude a los grupos que promueven la movilización social:

Habrá también, posiblemente, 'el 1 de mayo de los grupos conflictivos'. La prohibición de reuniones en la universidad hasta esa fecha hace pensar que existe el tema de que, como en años anteriores, haya en las calles de Madrid o Barcelona, Oviedo o Bilbao, grupos que pidan libertad sindical, distribuyan octavillas o agiten pancartas. En ellos —es fácil recordarlo - había de todo: gentes honestas que en su alma buscaban la justicia y agitadores partidarios del río revuelto; amigos de una España mejor y amigos del jaleo; hombres que utilizaban un procedimiento prohibido pero que hubieran preferido utilizar unos cauces legales más anchos, y hombres que seguirán utilizando los turbios canales aunque hubieran tenido las más anchas facilidades de expresión (Editorial, $\mathrm{n}^{\circ}$ 727, 27-04-1970, 1970: 5).

Por último, la revista habla de "1 de mayo de los curas", mencionando a los presbíteros que saldrán a las calles a defender la dignidad de las personas:

Estos se esforzarán por recordar que el primero de mayo es un día de exigencia humana y cristiana, que es la fecha en la que no se promueve la lucha de clases, pero sí el respeto a la persona como valor primario de toda economía, aunque la defensa de este respeto a la persona obligue a clamar y luchar contra individuos o clases que la aplasten. Gritarán que este es un día de solemne reflexión sobre el panorama de tantas reales injusticias como nos rodean. Lo gritarán sabiendo que no serán oídos, lo gritarán porque deben dar testimonio de la verdad, pero sin ignorar que los más -y sin que aquí los bautizados se diferencien en nada a los no practicantesbuscarán primero las 'añadiduras' y solo muy lejos y nunca 'el reino de Dios y su justicia' (Editorial, $\mathrm{n}^{\circ}$ 727, 27-04-1970, 1970: 5).

La revista mantiene la hipótesis de que, cuando finalice el día del 1 de mayo, "volverán a sus casas tranquilos y descansados los primeros, eufóricos y divertidos los segundos, nerviosos y humillados los terceros, un poco ingenuamente conformes con su esfuerzo los cuartos". El editorial apunta a los problemas que permanecerán

10 El 6 de junio de 1970 la revista recibe el primer expediente después de la publicación de la Ley de Prensa e Imprenta (Ley 14/1966, de 18 de marzo, 19 de marzo, 1966), en el que se acusa a este editorial de cometer una infracción contra el artículo 2 . La información de este hecho aparecía en el número 736 (Vida Nueva, $\mathrm{n}^{\circ}$ 736, 27-06-1970: 7). Este fue el único editorial que recibió un expediente, cuya sanción alcanzó las 5000 ptas. (Barrera, 2001: 131). Bernardino M. Hernando, redactor-jefe de la revista en aquel tiempo, explica que el motivo de aquella sanción "era creer que Vida Nueva estaba defendiendo el 1 de mayo del partido comunista". Además de eso, considera que "Vida Nueva no tenía buena fama en el Ministerio de Información" (Sánchez-Camacho, Comunicación personal, 17 de octubre, 2017). 
tras la celebración del 1 de mayo, señalando el grado de implicación de los españoles en asuntos de la vida pública, la pobreza, la ley sindical, el derecho a la huelga, la igualdad en la enseñanza y la política fiscal:

Y los problemas seguirán estando ahí: continuarán viviendo con menos de tres mil pesetas mensuales todos esos miles de hogares que el informe Foessa nos descubría recientemente; proseguiremos esperando ese debate sobre la ley sindical que transforme un tan mediano proyecto en una ley digna del siglo XX; seguirán -como recordaba hace días un diario madrileño-legalmente prohibidas las huelgas en España, pero existiendo de hecho; y no se nos habrá quitado el miedo de que la igualdad de oportunidades en la enseñanza, tan magníficamente programada en la ley de educación, se quede a la hora de la práctica en una 'aspiración' detenida por una falta de coraje en emprender una valiente y nueva política fiscal (Editorial, $\mathrm{n}^{0} 727,27-04-1970,1970: 5$ ).

En conclusión, refiriéndose al campo laboral, el editorial finaliza con esperanza expresando estos deseos para la celebración del Día Internacional de los Trabajadores:

¿Tal vez estamos pecando de pesimistas y en realidad el 1 de mayo será un acicate para todos, una búsqueda acorde de la justicia sin algaradas, un no decidido a todo triunfalismo que oculte los problemas, un común atreverse a mirar los problemas cara a cara? Sería hermoso que así fuera. Y nos sentiríamos avergonzados de ver algo tan serio como es esta fiesta del trabajo reducida a un día de excursiones y tortillas, festejos y gimnasia, algaradas y choques, $\mathrm{o}$, incluso, a una bella ocasión para escribir pastorales y predicar sermones inundados de abstractas y preciosas palabras (Editorial, $\mathrm{n}^{\mathrm{O}} 727,27-04-1970,1970: 5$ ).

El editorial del número 874, titulado "El cardenal fontanero", está dedicado a Stefan Trochta, un obispo checo que, nombrado cardenal in pectore en 1969, sufrió tanto la persecución del régimen nazi como la del comunista en la República Democrática Checoslovaca. El semanario destaca la ejemplaridad de un prelado que, tras estar ocho años en prisión y quedando prohibida su actividad episcopal, se dedicó humildemente a trabajar:

Ahora nos enteramos de su vida y de su cardenalato. Y conociéndole sentimos un poco de vergüenza de tantas cosas. Es fácil criticar a la Iglesia, presumir de avanzados; fácil de hablar de las estructuras opresoras y del cardenalato colorinesco; fácil soñar el regreso a un cristianismo evangélico desde la hermosa burguesía en que todos nosotros vivimos. Lo que ya no es tan fácil es no perder la sonrisa arreglando grifos mientras nosotros criticamos, hablamos y soñamos (Editorial, nº 874, 17-03-1973: 5).

\subsection{Sindicatos}

Como hemos comprobado al observar los resultados del análisis cuantitativo, Vida Nueva hace referencia a la situación sindical de España en sus editoriales. La categoría Sindicatos, sobre todo, está más presente en los editoriales de la revista entre 1969 y 1970, años previos a la Ley Sindical 2/1971 de 17 de febrero. Pero, al igual que con el Movimiento obrero, de los 14 editoriales en los que la categoría Sindicatos está presente, son solo 3 los textos dedicados a analizar este tema de manera más amplia. Aunque cuantitativamente su presencia sea algo menor que la del Movimiento obrero, la línea editorial de la revista defiende de manera explícita "la libertad, autonomía y representatividad sindical". Cuando lo hace, propone Justicia social, Participación: eclesial, Espíritu evangélico, Cambio, Participación: política, Participación: ciudadana, Derechos humanos, No a la solución militar/fuerza represiva, No a la violencia, Reflexión, Reconciliación y No a la confrontación. Mientras se discutía en las Cortes el proyecto de Ley, la revista ofrecía más cobertura al reconocimiento de las asociaciones sindicales. Sin embargo, es significativo el silencio de la línea editorial cuando la Ley finalmente se publica el 17 de febrero de 1971, ya que el proyecto que condujo a la Ley Sindical 2/1971 solo tuvo novedades de carácter administrativo. De esta manera, la Ley continuaba sin establecer la libertad de asociación y la participación ciudadana en España, y los Sindicatos Verticales seguían teniendo la misma vigencia (Ley Sindical 2/1971 de 17 de febrero, 1971).

En los números 699/700, un suplemento de la revista, llamado Pliego, está dedicado al borrador de la ley sindical. Titulado Un proyecto de ley sindical que abre muchos interrogantes, el reportaje recogía el curso de los acontecimientos haciendo uso de la hemeroteca. Aquel suplemento especial abría con un suelto en el que la revista mostraba "un sentimiento de decepción". Se hacía eco del diario Ya, que había manifestado su oposición con la promulgación de "una ley que en lo esencial - y sin otros cambios apreciables que el de la terminología - resultará igual que la realidad a la que va a sustituir, siendo semejante a una ley de hace treinta años". Vida Nueva discrepa cuando Ya afirma que se ha hecho lo "posible", ya que "la política es el arte de lo posible". La revista prefiere definir a la política como "el arte de hacer posible lo necesario. Y en el mundo sindical son muchas las 'necesidades' no cubiertas suficientemente por esta ley". El semanario no encuentra el modo de conciliar el proyecto sindical con los derechos humanos, los documentos de la Doctrina Social de la Iglesia o un informe de la Organización Internacional del Trabajo sobre la situación sindical del país (Vida Nueva, no 699/700, 11/18-10-1969: 19). 
En ese mismo número, el editorial, titulado "De la ley sindical y otras muchas cosas", no se muestra satisfecho con el proyecto de ley sindical, desgranado pormenorizadamente en las páginas interiores de la revista:

Y respecto al Sindical ahí tienen nuestros lectores un amplísimo informe. Informe triste, digámoslo por adelantado. Informe que, por lo demás, coincide con las críticas de amplios sectores de la opinión española y coincide aún más con ese gélido silencio que ha rodeado al proyecto [...] sin que nadie haya mostrado nada parecido al entusiasmo y en el que las voces laudatorias lo han hecho tímida y solitariamente presentándolo como el 'bien posible' que es muchas veces el modo de denominar el 'mal menor'.

[...] Y en la ley sindical se juega buena parte de la justicia y la felicidad de la España de hoy y de mañana. ¿Cómo podríamos callar entonces los cristianos? ¿Bastaría un cómodo silencio o unas hermosas palabras genéricas? Por otro lado, no hace aún tantos meses que los obispos españoles nos dieron un buen ejemplo con el documento sindical que nuestras páginas recogen. También ellos pudieron callarse. También ellos pudieron decir hermosas generalidades. Pero con su silencio y con el nuestro ¿cómo hubiéramos podido seguir siendo seguidores de Cristo? (Editorial, $\mathrm{n}^{\circ}$ 699/700, 11/18-10-1969: 5) ${ }^{11}$.

Unos meses más tarde, el editorial del número 708, titulado "Encaje de bolillos", se pregunta si el documento Nota sobre la Ley Sindical, acordado en la XI Asamblea Plenaria de la Conferencia Episcopal Española, abordaba de manera terminante el proyecto de Ley (Conferencia Episcopal Española, 1969), y se cuestiona si el texto aprobado es una "pálida, muy pálida sombra del publicado el año pasado"12. La revista subraya el desinterés de la prensa, añorando los tiempos en los que Juan XXIII era un personaje mediático: "Con su sicología desbordante, su sentido de rotura de hábitos y costumbres, [...] se convierte, primero en noticia, después en el amigo de todos los corazones" (Editorial, $\mathrm{n}^{\circ} 708$ 13-12-1969: 5).

Igualmente, el editorial considera que los comunicados oficiales se van haciendo cada vez más extraños "para un hombre habituado a llamar al pan, pan y al vino, vino". Y, molesto con el hecho de que la Iglesia española sea la "voz que clama en el desierto, no porque los hombres no quieran escucharla, sino porque nosotros nos hemos ido al desierto y no hemos salido de él", aboga por una Participación: eclesial que no esté politizada (No a la politización), en la línea de una mayor autonomía e independencia del Estado (Separación Iglesia-Estado):

Compárese, por ejemplo, el modo tajante con el que los cien encuestados del libro de Gironella -que nuestro pliego comenta- denuncian el maridaje de la Iglesia con los ricos y la política, con el cauteloso estilo del documento sindical emanado en estos días por nuestros obispos, y se verá cómo eclesiásticos y hombres medios de hoy 'emiten' en distinta onda (Editorial, $\mathrm{n}^{\mathrm{o}} 708$ 13-12-1969: 5).

El editorial del número 755, titulado "La ley sindical, problema de conciencia", comienza dando la noticia de que "por tercera vez la voz colectiva de nuestro episcopado ha vuelto a detenerse sobre el tema sindical". Esta vez, la revista considera que los obispos "han hablado a tiempo", "claramente y sin rodeos" a través de una Nota de la Comisión Episcopal de Apostolado Social ${ }^{13}$.

La revista valora positivamente que los obispos hayan hablado sobre "la libertad, autonomía y representatividad sindical". Para Vida Nueva el texto llega "justamente cuando los debates de las Cortes acaban prácticamente de iniciarse y cuando aún su aldabonazo puede ser francamente útil para sacudir las conciencias de los procuradores y del país". El editorial estima que si el documento Principios cristianos relativos al sindicalismo (Conferencia Episcopal Española, 1968) "quedaba lejos y se prestaba a interpretaciones minimizadoras, ninguna duda quedará ahora sobre un texto que no habla solo de principios, sino que los aplica

11 En la VII Asamblea Plenaria de la Conferencia Episcopal Española se había publicado el documento Principios cristianos relativos al sindicalismo, que hacía un llamamiento a la revisión de la antigua ley sindical (Conferencia Episcopal Española, 1968). Asimismo, las declaraciones de Pedro Cantero Cuadrado, arzobispo de Zaragoza, procurador de las Cortes Franquistas y presidente de la Comisión Episcopal de Medios de Comunicación social, venían a reconocer el "paso hacia adelante en relación con nuestras leyes sindicales de 1940". Pero expresaba su insatisfacción "en aspectos tan sustanciales como la representatividad y autonomía sindicales" y se comprometía a "presentar enmiendas" (Vida Nueva, no 699/700, 11/18-121969: 7). El suelto del reportaje especial de aquel mismo número de la revista, Un proyecto de ley sindical que abre muchos interrogantes, citaba al periódico ABC apelando a la reforma propuesta por el episcopado. La revista consideraba que mientras que el país fuera “confesionalmente católico - tesis que desearíamos ver superada, pero que pensamos ha de ser llevada a la práctica mientras sea ley-el texto de los obispos es — como dijera en su día ABC - moral y políticamente vinculante" (Vida Nueva, nº 699/700, 11/18-12-1969: 19).

12 Se refiere a Principios cristianos relativos al sindicalismo (Conferencia Episcopal Española, 1968), documento que en el editorial del número 755 la revista lo considera del todo insuficiente (Editorial, $n^{\circ} 755$ 7-11-1970: 5-6).

13 Vida Nueva, además de examinar en su editorial la Nota de la Comisión Episcopal de Apostolado Social, recoge íntegramente el breve documento en el interior de las páginas del número 755. El editorial parafrasea distintas partes del documento: "El actual proyecto de ley no recoge satisfactoriamente principios y criterios de la Doctrina Social de la Iglesia tan importantes como la libertad, autonomía y representatividad sindical. Estos principios, tal y como fueron expuestos en la declaración del 68, no eran las manifestaciones de opiniones privadas de los obispos sino un verdadero acto de Magisterio en su función de aplicar los principios cristianos a la realidad social de nuestro país. Si es verdad que es competencia de la autoridad civil el determinar en concreto las fórmulas más adecuadas a cada circunstancia, también lo es que cualquier solución que se adopte ha de ser tal que no invalide en la práctica aquellos principios" (Editorial, nº 755, 7/11/1970: 5-6). 
al juicio de valor moral que el propio proyecto de ley merece a los obispos" (Editorial, $\mathrm{n}^{\circ} 755,7-11-1970$ : $5-6)^{14}$. El editorial, termina valorando de esta manera el contenido del texto episcopal:

Y han hablado interpretando la voz del mundo del trabajo. Porque es claro que los obispos no están defendiendo ideas personales, ni siquiera una norma moral más o menos abstracta o una doctrina social que, elaborada en un gabinete, combatiera otras fórmulas o doctrinas sociales. Los obispos no están haciendo otra cosa que proclamar y recordar unos derechos que son poseídos y reclamados por esas masas españolas para quienes se hace la ley (Editorial, $\left.n^{\circ} 755,7-11-1970: 5-6\right)$.

\section{Conclusiones}

Durante el tardofranquismo, la revista Vida Nueva se implica y afronta en sus editoriales la temática de los sindicatos y el movimiento obrero. Son tiempos complicados para la libertad de prensa. El hecho de significarse, poniendo el foco de atención informativa en los conflictos existentes, y provocar de este modo la reflexión y la movilización de corrientes de opinión, supone un riesgo para la publicación. Vida Nueva asume ese reto con sus consecuencias y marca desde sus editoriales una línea de pensamiento y actuación comprometida. Tanto es así, que es sancionada debido a un editorial que promueve la participación ciudadana en el Día Internacional de los Trabajadores. Además, para el establecimiento de una defensa efectiva del mundo obrero, en armonía con la Doctrina Social de la Iglesia y, en concreto, con la Nota de la Comisión Episcopal de Apostolado Social, la revista se muestra a favor de las asociaciones sindicales. En ese sentido, considera que la Ley Sindical de 1971 no responde a las expectativas despertadas en torno a la libertad, autonomía y representatividad. A continuación, se presentan algunas conclusiones más específicas que el semanario desarrolla en su línea editorial:

- Vida Nueva recibe su primer expediente por el tratamiento editorial sobre el Día Internacional de los Trabajadores en España. El semanario expresa esperanza en la eficacia de dicha celebración y considera que ha de ser un estímulo para la búsqueda de la justicia. La revista presta atención a la forma de celebrar tal acontecimiento, analizando las distintas maneras de vivirlo. De modo implícito, reprueba la actitud de aquellos que convierten dicho día en una jornada de ocio. Igualmente, critica la Demostración sindical del Estadio Santiago Bernabéu que, según el semanario, ocultará los conflictos laborales del país, las manifestaciones callejeras y los datos relativos al bajo nivel de renta nacional. Asimismo, aludiendo al amplio sector que fomenta la movilización social, valora a quienes de manera honesta buscan la justicia social y se muestra disconforme con quienes promueven la mera agitación. La revista también defiende la movilización de los presbíteros para defender los derechos de los trabajadores, la dignidad de las personas y el "reino de Dios y su justicia". Y apuesta por la implicación de los españoles en asuntos del trabajo y de la vida pública cuando finalice el día del 1 de mayo, criticando la prohibición de las huelgas en España, a pesar de que estas se efectúen en la práctica.

- Un año antes de ser publicada la Ley Sindical 2/1971, la revista considera que debe abrirse el debate sobre este asunto, calificando de "mediano proyecto" aquella legislación en ciernes. Por ello, hace un llamamiento a que se programe una ley sindical "digna del siglo XX", subrayando el poco entusiasmo existente entre la ciudadanía ante esta medida legislativa. Porque Vida Nueva considera que, con dicha ley, España "se juega buena parte de la justicia y la felicidad".

- El semanario valora que la Iglesia se pronuncie sobre el tema de los sindicatos, pero considera insuficientes los dos primeros documentos publicados por la Conferencia Episcopal: Principios cristianos relativos al sindicalismo (Conferencia Episcopal Española, 1968) y Nota sobre la Ley Sindical (Conferencia Episcopal Española, 1969). Y, comparando sendos documentos con las intervenciones públicas de Juan XXIII, aboga por comunicados más determinantes. Sin embargo, la revista elogia el tercer texto publicado por la jerarquía eclesial sobre este asunto, titulado Nota de la Comisión Episcopal de Apostolado Social, por defender la libertad, autonomía y representatividad sindical. Asimismo, estima que, esta vez, los obispos han hablado "a tiempo" y de manera clara, antes de la publicación de la ley.

- La revista aprecia la labor de los sacerdotes obreros, haciendo memoria del prelado checo Stefan Trochta y del llamado Padre Jacques Loew. A través del reconocimiento del trabajo del obispo y presbítero obrero, la revista subraya la dimensión social de los creyentes, revelando la vinculación existente entre la evangelización y la justicia. Y, aunque en España hubiera sectores católicos que rechazaban este

14 Asimismo, el 11 julio de 1970 se había publicado el "Comunicado final de la XII Asamblea Plenaria de la Conferencia Episcopal Española sobre La Iglesia y los pobres", que reconocía "el derecho que todo hombre tiene a asociarse y reunirse libremente para fines lícitos, como es la promoción de sus intereses profesionales dentro de auténticos sindicatos representativos, y a la intervención en la cosa pública a través de cauces eficaces de participación política" (Conferencia Episcopal Española, 1970). Sin embargo, la Ley Sindical, publicada meses después, desoiría aquellas llamadas episcopales al reconocimiento de los sindicatos (Ley Sindical 2/1971 de 17 de febrero, 1971). 
vínculo, el semanario se posiciona en esta línea acogida por el Concilio Vaticano II, que definió la misión de la Iglesia con respecto al orden temporal.

- Finalmente, hay que tener presente las palabras de Martín Descalzo cuando terminaba su etapa como director, llegando a reconocer que, debido a la represión de la dictadura, se ve obligado a "practicar el arte de decir medias verdades o de rebozar las verdades enteras con abundante ración de vaselina" (Editorial, $\mathrm{n}^{\circ}$ 1011, 03-01-1976: 5). Esta declaración del director del semanario muestra las limitaciones de la libertad de prensa. De ahí que se infiera que Vida Nueva no pudiera plantear abiertamente la cuestión social en sus editoriales, teniendo que verse obligada a imponerse cierta autocensura debido a los secuestros administrativos y las sanciones impuestas por la Ley de Prensa e Imprenta de 1966.

En consecuencia, pese a los condicionamientos de la dictadura franquista, Vida Nueva defiende los derechos del mundo obrero y promueve una ley sindical que responda a la libertad, autonomía y representatividad de las asociaciones. A la luz de la Constitución pastoral del Concilio Gaudium et Spes, esta revista religiosa y social entiende que la Iglesia, estando desligada del nacionalcatolicismo, no puede vivir al margen del mundo, y que la realidad espiritual y temporal son dimensiones complementarias en el mensaje cristiano. De ahí que se implique en la transformación social de España e intérprete que su papel, como el del resto de la prensa, sea el de "contribuir a la búsqueda de soluciones concretas en todos los órdenes" (Editorial, nº 671, 29-03-1969: 5).

\section{Bibliografía}

Barrera, C. (2001). "Revistas católicas y conflictos con el poder político en el tardofranquismo". En: Anuario de la Historia de la Iglesia, $\mathrm{n}^{\circ} 10$, pp. 101-142.

Cárcel Ortí, V. (1997). Pablo VI y España. Fidelidad, renovación y crisis (1963- 1978). Madrid: BAC.

Casanova Ruiz, J. (2005). La Iglesia de Franco. Barcelona: Crítica.

Castillo, S. (2008). Historia de la UGT. Un sindicalismo consciente, 1873-1914. Madrid: Siglo XXI de España.

Castillo Esparcia, A.; Castillero Ostio, E. (2019). "Las relaciones Iglesia-Estado durante el régimen franquista. Estudio de su evolución histórica reflejada en la celebración de actos oficiales". En Historia y comunicación social, Vol. 24, $\mathrm{n}^{\mathrm{o}} 1$, pp. 61-76.

Concilio Vaticano II. (1966). Documentos del Concilio Vaticano II. La Santa Sede. Recuperado de http://www.vatican.va/ archive/hist_councils/ii_vatican_council/index_sp.htm [Consulta: 30/11/2019].

Conferencia Episcopal Española. (21 de julio de 1968). Principios cristianos relativos al sindicalismo. Recuperado de https://www.conferenciaepiscopal.nom.es/archivodoc/jsp/index.jsp?_forward= [Consulta: 30/11/2019].

Conferencia Episcopal Española. (4 de diciembre de 1969). Nota sobre la Ley sindical. Recuperado de https://www. conferenciaepiscopal.nom.es/archivodoc/jsp/system/win_main.jsp [Consulta: 30/11/2019].

Conferencia Episcopal Española. (11 de julio de 1970). La Iglesia y los pobres. Recuperado de https://www. conferenciaepiscopal.nom.es/archivodoc/jsp/system/win_main.jsp [Consulta: 30/11/2019].

Cuenca Toribio, J. M. (2001). Sindicatos y partidos católicos españoles 1977: ¿fracaso o frustración? 1870-1977. Madrid: Unidad Editorial.

Decreto 779/1967, de 20 de abril de 1967. (21 de abril de 1967). Por el que se aprueban los textos refundidos de las Leyes Fundamentales del Reino. En: Boletín Oficial del Estado. Recuperado de http://www.boe.es/buscar/doc. php?id=BOE-A-1967-40312 [Consulta: 30/11/2019].

Decreto ley 7/1974 de 21 de diciembre de 1974. (23 de diciembre de 1974). Por el que se aprueba el Estatuto Jurídico del Derecho de Asociación Política. Boletín Oficial del Estado. Recuperado de http://www.boe.es/boe/dias/1974/12/23/ pdfs/A26045-26049.pdf [Consulta: 30/11/2019].

Editorial, Vida Nueva, $\mathrm{n}^{\circ}$ 655, 07-12-1968.

Editorial, Vida Nueva, n ${ }^{\circ} 671,29-03-1969$.

Editorial, Vida Nueva, n ${ }^{\circ}$ 699/700, 11/18-10-1969.

Editorial, Vida Nueva, $\mathrm{n}^{\circ} 708,13-12-1969$.

Editorial, Vida Nueva, $\mathrm{n}^{\circ} 719,28-02-1970$.

Editorial, Vida Nueva, n ${ }^{\circ} 727,27-04-1970$.

Editorial, Vida Nueva, $\mathrm{n}^{\circ}$ 755, 7-11-1970.

Editorial, Vida Nueva, n $^{\circ} 874,17-03-1973$.

Editorial, Vida Nueva, n $^{\circ}$ 971, 01-03-1975.

Editorial, Vida Nueva, $\mathrm{n}^{\circ}$ 1000, 11/18-10-1975.

Editorial, Vida Nueva, $\mathrm{n}^{\circ}$ 1011, 03-01-1976.

García Galera, M. D y Berganza Conde, M. R. (2005). El método científico aplicado a la investigación en Comunicación Mediática. En M. R. Berganza Conde y J. A. Ruiz San Román (dir.), Investigar en Comunicación. Guía práctica de métodos y técnicas de investigación social en Comunicación. Madrid: McGraw-Hill, pp. 19-42.

Hernández-Sampieri, R. y Mendoza Torrres, C. P. (2018). Metodología de la investigación: las rutas cuantitativa, cualitativa y mixta. México: Mc Graw Hill. 
Juan XXIII. (15 de mayo de 1961). Carta Encíclica Mater et Magistra. La Santa Sede. Recuperado de http://w2.vatican. va/content/john-xxiii/es/encyclicals/documents/hf_j-xxiii_enc_15051961_mater.html [Consulta: 30/11/2019]

Laboa, J. M. (2002). Historia de la Iglesia IV: Época contemporánea. Madrid: BAC.

León XIII. (5 de mayo de 1891). Carta Encíclica Rerum novarum. La Santa Sede. Recuperado de http://w2.vatican.va/ content/leo-xiii/es/encyclicals/documents/hf_1-xiii_enc_15051891_rerum-novarum.html [Consulta: 30/11/2019].

Ley 14/1966, de 18 de marzo de 1966. (19 de marzo de 1966). De Prensa e Imprenta. En: Boletín Oficial del Estado. Recuperado de http://www.boe.es/boe/dias/1966/03/19/pdfs/A03310-03315.pdf [Consulta: 30/11/2019]

Ley Sindical 2/1971 de 17 de febrero de 1971 (19 de febrero de 1971). En: Boletín Oficial del Estado. Recuperado de https://www.boe.es/buscar/doc.php?id=BOE-A-1971-230 [Consulta: 30/11/2019].

Martín de Santa Olalla, P., y Serrano Oceja, J. F. (2016). 50 años de la Conferencia Episcopal Española. Madrid: Encuentro.

Martínez Hernando, B. (1973). Historia de Vida Nueva. Los últimos 30 años del catolicismo español a través de una revista. Madrid: Tesina de fin de carrera en la Escuela Oficial de Periodismo.

Montero, F. (2009). La Iglesia: de la colaboración a la disidencia (1956-1975). Madrid: Encuentro.

Núñez de Arenas, M.; Tuñón de Lara, M. (1970). Historia del movimiento obrero español. Barcelona: Nova Terra .

Orella Martínez, J. L. (2009). El Estado en obras (1959-1975). En J. Paredes (dir.), Historia de España Contemporánea. Barcelona: Sello Editorial, pp. 823-851.

Ortega, J. L. (1979). “La Iglesia española desde 1939 hasta 1976”. En R. GarcíaVilloslada (dir.), Historia de la Iglesia en España V. La Iglesia en la España contemporánea (1808-1975). Madrid: BAC, pp. 665-714.

Pablo VI. (26 de marzo de 1967). Carta Encíclica Populorum Progressio. La Santa Sede. Recuperado de http://w2.vatican. va/content/paul-vi/es/encyclicals/documents/hf_p-vi_enc_26031967_populorum.html [Consulta: 30/11/2019].

Payne, S. (1987). El régimen de Franco. Madrid: Alianza Editorial.

Peirats Valls, J. (1991). Breve historia de la CNT. Móstoles, Madrid: Madre Tierra.

Pío X. (11 de junio de 1905). Carta Encíclica Il fermo proposito. La Santa Sede. Recuperado de https://w2.vatican.va/ content/pius-X/en/encyclicals/documents/hf_p-X_enc_11061905 il-fermo-proposito.html [Consulta: 30/11/2019].

Pío XI. (15 de mayo de 1931). Carta Encíclica Quadragesimo Anno. La Santa Sede. Recuperado de http://w2.vatican.va/ content/pius-xi/es/encyclicals/documents/hf_p-xi_enc_19310515_quadragesimo-anno.html [Consulta: 30/11/2019].

Rodríguez Labandeira, J. "Relaciones laborales, sindicalismo y movimiento obrero." En Paredes J. (1999), Historia Universal Contemporánea. Barcelona: Ariel, pp. 204-230.

Sánchez-Camacho, J. (17 de octubre, 2017). Comunicación personal con Bernardino M. Hernando, redactor-jefe de Vida Nueva en el periodo analizado. Madrid.

Sánchez-Camacho, J. (2018). El impacto del Concilio Vaticano II y la transformación social de la España tardofranquista en la línea editorial de Vida Nueva (1968-1975). Salamanca: Tesis doctoral, Universidad Pontificia de Salamanca.

Sánchez Aranda, J. J. (2005). Análisis de contenidos cuantitativos de medios. En M. R. Berganza Conde y J. A. Ruiz San Román (dir.), Investigar en Comunicación. Guía práctica de métodos y técnicas de investigación social en Comunicación. Madrid: McGraw-Hill, pp. 207-228.

Santamaría, L. (1990). El comentario periodístico. Los géneros persuasivos. Madrid: Paraninfo.

Tusell, J. (1984). Franco y los católicos. Madrid: Alianza Universidad.

Tusell, J. (1989). La España de Franco. Madrid: Historia 16.

Tusell, J. (1990). Manual de Historia de España. Siglo XX (Vol. 6). Madrid: Historia 16.

Urchaga, J. D. (2009). Análisis de contenido. En R. Reyes (dir.), Diccionario Crítico de Ciencias Sociales, vol.1. Madrid y México: Plaza y Valdés, pp. 147-151.

Vida Nueva, $\mathrm{n}^{\circ}$ 699/700, 11/18-10-1969:7.

Vida Nueva, no 699/700, 11/18-10-1969: 19-51.

Vida Nueva, $\mathrm{n}^{\mathrm{o}} 736,27-06-1970$.

Watt, N., Rey, P. y Urchaga, J. D. (2010). Vida Nueva en la Transición; Iglesia y sociedad españolas en la línea editorial del semanario de PPC. Barcelona: Ediciones STJ.

Van Gestel, C. (1964). La Doctrina social de la Iglesia. Barcelona: Herder.

Wimmer, R. D. y Dominick, J. R. (1996). La investigación científica de los medios de comunicación. Barcelona: Bosch Casa Editorial S.A. 